\title{
МОДЕЛЮВАННЯ ФУНКЦЙ ШТРАФІВ І ЗАОХОЧЕНЬ ДЛЯ ЕФЕКТИВНОГО КЕРУВАННЯ В ІЄРАРХІЧНІЙ СИСТЕМІ ЗАМОВНИК - ВИРОБНИК
}

\author{
МОДЕЛИРОВАНИЕ ФУНКЦИЙ ШТРАФОВ И ПООЩРЕНИЙ ДЛЯ \\ ЭФФЕКТИВНОГО УПРАВЛЕНИЯ В ИЕРАРХИЧЕСКОЙ СИСТЕМЕ ЗАКАЗЧИК - \\ ПРОИЗВОДИТЕЛЬ
}

\section{MODELING OF FUNCTIONS OF FINANCIAL PENALTIES AND REWARDS FOR EFFECTIVE MANAGEMENT IN A HIERARCHICAL SYSTEM THE CUSTOMER - MANUFACTURER}

\begin{abstract}
У статті побудована модель економічних відношень між Замовником і Виробником в дворівневій ієрархічній системі керування на короткотерміновий період часу. Припускається, що Замовник не може сподіватися отримати від Виробника точно встановлений обсяг продукиії, але може впливати на обсяги виробництва, враховуючи інтереси та цілі Виробника. Замовник забезпечує виробничий процес фондами, але не займається наймом робочої сили, виплатою заробітної плати - ие функиія Виробника, як $i$ безпосередня організаџія процесу виробництва. Відома кінцева иіна одиниці продукту, за якою Замовник буде розраховуватись із Виробником. Способом впливу Замовника на діі Виробника є додаткова винагорода або штраф, щзо виплачується Замовником Виробнику в залежності від результатів його діяльності. Виробник при прийнятті рішень, щодо власних дій, знає умови заохочення та штррафування. В даній роботі запропонована процедура визначення функиії штрафів (заохочень) за допомогою методу параметризаціі функції таким чином, щуоб стимулювати виробництво в певному обсязі і не менше даного рівня.
\end{abstract}

Ключові слова: кібернетична система, ієрархічна система, функція штрафів та премій, багатокритеріальні задачі прийняття рішень.

В статье построена модель экономических отношений между Заказчиком $u$ Производителем в двухуровневой иерархической системе управления на краткосрочный период времени. Предполагается, что Заказчик не может надеяться получить от Производителя точно установленный объем продукиии, но может влиять на объемы производства, учитывая интересы и чели Производителя. Заказчик обеспечивает производственный прочесс фондами, но не занимается наймом рабочей силь, выплатой заработной платы - это функция Производителя, как и непосредственная организация процесса производства. Известна конечная цеена единииь продукта, по которой Заказчик будет рассчитываться с Производителем. Способом влияния Заказчика на действия Производителя есть дополнительная вознаграждение или штраф, который выплачивается Заказчиком Производителю в зависимости от результатов его деятельности. Производитель при принятии решений, относительно собственных действий, знает условия поощрения и штрафов. В данной работе предложена прочедура 
определения функции штрафов (поощрений) с помощью метода параметризации функции таким образом, чтобы стимулировать производство в определенном объеме и не меньше данного уровня.

Ключевые слова: кибернетическая система, иерархическая система, функция штрафов и премий, многокритериальные задачи принятия решений.

In article, we built a model of economic relations between the Customer and the Manufacturer in a two-level hierarchical control system for a short period of time. It is assumed that the Customer cannot hope to obtain from the Manufacturer determined the volume of production, but can affect the volume of production, taking into account the interests and goals of the Manufacturer. The Customer provides a production process of the funds, but is not involved in recruitment; payment of wages is a function of the Manufacturer, as the immediate organization of the production process. Final unit price of the product, which the Customer will be calculated with the Manufacturer, is known. By way of the influence of the Customer on the actions of the Manufacturer, there is an additional fee or penalty payable by the Customer to the Manufacturer depending on the results of its activity. Manufacturer when making decisions regarding their own actions knows the conditions of promotion and fines. In this paper, a procedure is proposed to determine the function of the fines (rewards) using the method of parameterization functions in such a way as to stimulate the production of a certain amount and not less than a given level.

Keywords: cybernetic system, a hierarchical system, the function of penalties and rewards, multicriteria decision tasks.

Вступ. Головна особливість систем керування полягає в тому, що в системі існують вільні функції, якими може розпорядитися в своїх інтересах суб'єкт, асоційований із системою. При вивченні систем керування користуються описом, який відображає рівень знань дослідника і суб'єкта, а отже, є суб'єктивним. Із кібернетичною системою асоціюється вже ціла група суб'єктів, що мають власні цілі та уявлення про систему, і кожний 3 яких може здійснювати вплив на систему в цілому. До того ж ці уявлення суб'єктів не $є$ тотожними. Отже, вивчення кібернетичних систем може проводитись лише з позицій певного суб'єкта, грунтуючись на його цілях і на його уявленні про ситуацію. Вибір керування цього суб'єкта буде визначатися не тільки його ціллю. Крім того, важливо знати, що думають інші суб'єкти про цілі цього суб'єкта, з позицій якого ведеться аналіз, на базі якої інформації вони приймають рішення, що вони знають про його інформованість і т. ін. В реальних системах подібного типу не існує ланки (елемента), де б концентрувалась вся «об’єктивна» інформація про систему [1].

Неможливість централізованої переробки інформації за даний час потрібним чином (обгрунтувати рішення) приводить до того, що рішеннz виявляються недостатньо продуманими, що еквівалентно високому рівню невизначеності. Тому приходиться «делегувати» права прийняття рішення нижнім ланкам ієрархії. Як тільки окремій частині організму «делегуються» права по прийняттю рішень, вона набуває певних можливостей для досягнення власних цілей, які їй об'єктивно присутні, тобто вона становиться 
самостійним організмом, і неминучим чином виникають певні суперечності між частиною і цілим. Але суб'єкти об'єднуються в ієрархічну систему тому, що це їм вигідно: обмежуючи свої бажання, вони при цьому краще забезпечують свою стабільність.

Простішою схемою ієрархічної системи керування $є$ двоступенева структура віяла. В цій системі існує один привілейований суб'єкт (Замовник), який має можливість керувати іншими суб'єктами (Виробниками). Нерівноправність суб'єктів проявляється в тому, що саме Замовник назначає правила формування впливів, які залежать тим чи іншим чином від дій Виробників, і Виробникам ці правила становляться відомими в той момент, коли вони приймають рішення, щодо їх власних дій. Тим самим Замовник має можливість (правило першого ходу) направляти в потрібне русло зусилля нижніх ланок. Замовник передає певну інформацію нижнім ланкам - це для нього може виявитися вигідним [5]. На цьому принципі грунтується дія економічних механізмів керування, одним із яких є керування за допомогою штрафів та заохочень. Але навіть для такого простого випадку ієрархічної системи, яку ми розглядаємо, розв'язок задачі ефективного визначення оптимального штрафу потребує створення спеціальних методів. Деякі підходи до розв'язку цієї задачі наведені в [1-5].

Постановка завдання. Розглянемо процедуру прийняття рішень для короткотермінового періоду часу (статичну задачу) з точки зору Замовника в ієрархічній системі керування Замовник - Виробник за умови конфліктної ситуації, де партнери нерівноправні. Впливами Замовника на Виробників будуть виступати штрафи і заохочення, які Замовнику для досягнення власної мети потрібно завчасно визначити, виходячи 3 можливих результатів дій Виробників.

Методологія. При аналізі і проектуванні ієрархічних систем керування використовуються схеми міркувань і структура гіпотез, приклади яких можна знайти в [1-5].

Оскільки між Виробником і Замовником виникають суперечності, які моделюються багатокритеріальними задачами прийняття рішень, то для їх розв’язку використовуються певні методи, зокрема, метод провідного критерію.

Вибір класу функцій до якого повинні належати штрафи і заохочення, це спеціальна і складна проблема [2]. Для визначення функції штрафів (заохочень) будемо використовувати параметризацію цієї функції, тобто представлення iї в залежності від декількох параметрів.

Результати дослідження. Результат функціонування Замовника визначається результатами виробничої діяльності Виробника - сам Замовник ніякої продукції не виробляє. Тому цільова функція Замовника визначається продукцією, яку виробляє Виробник. Припустимо, що Замовник не може 
сподіватися отримати від Виробника точно встановлені обсяги виробництва продукту $P$ (лише в деяких межах). Наприклад, в галузі сезонного будівництва, де діють такі випадкові чинники, як погодні умови, людський фактор. Але він може впливати на величину $P$, враховуючи інтереси та цілі Виробника. Будемо вважати, що обсяг виробництва продукту $P$ однозначно визначається обсягом фондів $K$ і кількістю робочої сили $L: P=f(K, L)$. Нехай Замовник забезпечує виробничий процес фондами (ресурсами та матеріалами), але не займається наймом робочої сили, виплатою заробітної плати працівникам - це функція Виробника, як і безпосередня організація процесу виробництва. Тобто величина фондів $K$ фіксована, а обсяг виробленої продукції однозначно визначається кількістю робочої сили $L$. Величина $L$ тут $\epsilon$ керуючим параметром, який повністю знаходиться в розпорядженні Виробника.

Як відомо, виробнича функція описує граничні можливості виробництва. Існують різні способи апроксимації виробничої функції $f$. Візьмемо, наприклад, в якості виробничої функції функцію Кобба-Дугласа $P=\alpha K^{\beta} L^{1-\beta}$, де $\alpha, \beta$ - характеристики виробництва. Знаючи певний технологічний процес і маючи статистичну інформацію, Замовник може розрахувати ці показники та визначити середньостатистичний обсяг виробництва $P$ за відомими фондами $K$ та робочою силою $L$.

Для того, щоб керувати діями Виробника, Замовник повинен мати деякі способи впливу на цілі Виробника, певну гіпотезу щодо яких він може припустити. Наприклад, будемо вважати, що Виробник прагне максимізувати власний прибуток $J=c P-\omega L \rightarrow \max$, де $c-$ кінцева ціна одиниці продукту Виробника, за якою Замовник буде розраховуватись із Виробником, $\omega-$ середня ставка заробітної плати робітників.

Замовник може вплинути на величину доходу Виробника, спонукаючи його тим самим діяти в напрямку, що є вигідним Замовнику. Замовник може безпосередньо впливати не на структуру, а на величину цільової функції Виробника J. Одним із способів впливу Замовника на дії Виробника $\epsilon$ додаткова винагорода або штраф $\varphi(P)$, що виплачується Замовником Виробнику в залежності від результатів його діяльності. Тоді цільова функція Виробника може бути представлена у вигляді $J=c P-\omega L+\varphi(P) \rightarrow \max$, причому $\omega L \leq c P$.

До того ж ми вважаємо, що Виробник ефективно керує процесом виробництва, не порушуючи його якості, i, зрозуміло, що в інтересах Замовника, щоб Виробник при прийнятті рішень щодо власних дій знав умови заохочення (винагороди) та штрафування (покарання), тобто значення функції $\varphi(P)$ в залежності від $P$. 
Цільова функція - критерій ефективності функціонування Замовника тоді має вигляд $T=(s-c) P-\varphi(P) \rightarrow \max$, де $s \geq c$ - кінцева ціна одиниці продукту Замовника.

Функцію штрафів та заохочень будемо шукати у вигляді: $\varphi(P)=\lambda(P)\left(P-P_{\min }\right)^{2}-c P+\omega L$, де $P_{\min }-$ мінімальний допустимий обсяг виробництва. В цьому випадку вираз цільової функції Виробника набуде вигляду $J=\lambda(P)\left(P-P_{\min }\right)^{2} \rightarrow \max$.

Задача полягає в тому, щоб знайти функцію $\lambda=\lambda(P)$.

3 точки зору Замовника для забезпечення максимуму свого прибутку Виробник має так розпоряджатися своїми ресурсами, щоб обсяг його продукції був не менший за $P_{\min }$ і в кращому випадку дорівнював $\hat{P}$. Нехай $\lambda\left(P_{\min }\right)=0, J<0$ при $P<P_{\text {min }}$, і швидкість зміни функції $J$ зростає при зміні обсягів $P$ в околі $P_{\min }$. Тоді розглянемо $\lambda(P)$, наприклад. у вигляді квадратичної функції: $\lambda(P)=a\left(P-P_{\text {min }}\right)^{2}+b\left(P-P_{\text {min }}\right)$, де $a<0$.

Підберемо такі коефіцієнти $a$ та $b$, щоб максимум досягався в точці $\hat{P}$, тобто $\hat{P}$ - точка максимуму функції $J=a\left(P-P_{\min }\right)^{4}+b\left(P-P_{\min }\right)^{3}$.

Перша похідна функції $J$ дорівнює

$J^{\prime}(P)=\left(P-P_{\text {min }}\right)^{2}\left(4 a\left(P-\left(\frac{-3 b}{4 a}+P_{\text {min }}\right)\right)\right)$.

В точці $\widehat{P}$ виконується рівність $\hat{P}-\left(\frac{-3 b}{4 a}+P_{\min }\right)=0$.

Тоді $b=\frac{-4 a\left(\hat{P}-P_{\min }\right)}{3}>0$, оскільки $a<0$.

Перевіримо, що в точці $\hat{P}$, дійсно, досягається максимум. Для цього знайдемо другу похідну функції $J$ в точці $\widehat{P}$.

$$
J^{\prime \prime}(\hat{P})=12 a\left(\hat{P}-P_{\text {min }}\right)^{2}+6 b\left(\hat{P}-P_{\text {min }}\right)=4 a\left(\hat{P}-P_{\text {min }}\right)^{2}<0 .
$$

Крім того, $J^{\prime \prime}(P)=12 a\left(P-P_{\text {min }}\right)\left(\left(P-P_{\text {min }}\right)-\frac{2}{3}\left(\hat{P}-P_{\text {min }}\right)\right)<0 \quad$ при $P<P_{\min }$. Це означає, якщо обсяги продукції зменшуються від значення $P_{\min }$ рівними частками, то значення штрафів змінюються все більшими частками.

Якщо ж обсяги продукції збільшуються від значення $P_{\min }$ до обсягу $\bar{P}=P_{\text {min }}+\frac{2}{3}\left(\hat{P}-P_{\min }\right)$ рівними частками, то значення премії змінюються все більшими частками. Вираз для $\bar{P}$ показує доцільність розгляду в якості функції $J$ полінома четвертого степеня, аніж кубічного, оскільки в останньому випадку коефіцієнт при $\left(\hat{P}-P_{\min }\right)$ дорівнює $\frac{1}{2}$.

Нехай максимальне значення функції прибутку Виробника $J$ в точці $\widehat{P}$ дорівнює $\hat{Y}$, тоді

$$
\hat{Y}=a\left(\hat{P}-P_{\text {min }}\right)^{4}-\frac{4 a\left(\hat{P}-P_{\text {min }}\right)}{3}\left(\hat{P}-P_{\text {min }}\right)^{3}=\frac{-a}{3}\left(\hat{P}-P_{\text {min }}\right)^{4} .
$$


Звідси можна знайти значення параметрів $a$ та $b$ в залежності від $P_{\text {min }}, \hat{P}$ та $\hat{Y}$.

$$
a=-\frac{3 \hat{Y}}{\left(\hat{P}-P_{\text {min }}\right)^{4}}, b=\frac{4 \hat{Y}}{\left(\hat{P}-P_{\text {min }}\right)^{3}}
$$

Оскільки ми розглядаємо двокритеріальну задачу:

$$
\begin{gathered}
J=a\left(P-P_{\text {min }}\right)^{4}+b\left(P-P_{\text {min }}\right)^{3} \rightarrow \max , \\
T=(s-c) P-\varphi(P)=s P-\omega L-a\left(P-P_{\text {min }}\right)^{4}-b\left(P-P_{\text {min }}\right)^{3} \rightarrow \text { max }
\end{gathered}
$$

то для знаходження компромісного рішення скористаємося методами раціонального вибору з множини альтернатив.

Дана задача розглядається з точки зору Замовника. Нехай його першим пріоритетом є стимулювання виробництва продукції в кількості $\hat{P}$. Тоді провідним критерієм для Замовника виступає цільова функція Виробника, а цільова функція Замовника переводиться в обмеження.

Таким чином, одержуємо задачу нелінійного програмування 3 одним критерієм:

$$
\begin{gathered}
J=-\frac{3 \hat{Y}\left(P-P_{\text {min }}\right)^{4}}{\left(\hat{P}-P_{\text {min }}\right)^{4}}+\frac{4 \hat{Y}\left(P-P_{\text {min }}\right)^{3}}{\left(\hat{P}-P_{\text {min }}\right)^{3}} \rightarrow \text { max }, \\
T=s P-\omega\left(\frac{P}{\alpha K^{\beta}}\right)^{\frac{1}{1-\beta}}+\frac{3 \hat{Y}\left(P-P_{\text {min }}\right)^{4}}{\left(\hat{P}-P_{\text {min }}\right)^{4}}-\frac{4 \hat{Y}\left(P-P_{\text {min }}\right)^{3}}{\left(\hat{P}-P_{\text {min }}\right)^{3}} \geq \delta(s-c) P, \\
\omega\left(\frac{P}{\alpha K^{\beta}}\right)^{\frac{1}{1-\beta}} \leq c P, 0 \leq \delta \leq 1 .
\end{gathered}
$$

При цьому $\delta$ виступає в ролі мінімально допустимого, 3 точки зору Замовника, відсотка очікуваного прибутку після виплати премії.

3 обмеження, що накладене на $T$, при $P_{\min }<P<\hat{P}+\frac{\hat{P}-P_{\min }}{3}$ одержуємо наступне співвідношення для $\hat{Y}$ :

$$
\hat{Y} \leq \frac{\left(\hat{P}-P_{\text {min }}\right)^{4}}{\left(P-P_{\text {min }}\right)^{3}} \frac{\left(\delta(s-c) P-s P+\omega\left(\frac{P}{\alpha K^{\beta}}\right)^{\frac{1}{1-\beta}}\right)}{\left(3\left(P-P_{\text {min }}\right)-4\left(\hat{P}-P_{\text {min }}\right)\right)} .
$$

Оскільки оптимальним планом є обсяг $\widehat{P}$, то

$$
\begin{aligned}
\hat{Y} \leq & \delta c \hat{P}+(1-\delta) s \hat{P}-\omega\left(\frac{\hat{P}}{\alpha K^{\beta}}\right)^{\frac{1}{1-\beta}}= \\
& =c \hat{P}-\omega\left(\frac{\hat{P}}{\alpha K^{\beta}}\right)^{\frac{1}{1-\beta}}+(1-\delta)(s-c) \hat{P}
\end{aligned}
$$

Таким чином, функція штрафів (заохочень) має вигляд: 


$$
\begin{aligned}
\varphi(P)= & -\frac{3 \hat{Y}\left(P-P_{\min }\right)^{4}}{\left(\hat{P}-P_{\min }\right)^{4}}+\frac{4 \hat{Y}\left(P-P_{\min }\right)^{3}}{\left(\hat{P}-P_{\min }\right)^{3}}-c P+\omega\left(\frac{\hat{P}}{\alpha K^{\beta}}\right)^{\frac{1}{1-\beta}}, \text { де } \\
& c \hat{P}-\omega\left(\frac{\hat{P}}{\alpha K^{\beta}}\right)^{\frac{1}{1-\beta}} \leq \hat{Y} \leq c \hat{P}-\omega\left(\frac{\hat{P}}{\alpha K^{\beta}}\right)^{\frac{1}{1-\beta}}+(1-\delta)(s-c) \hat{P} .
\end{aligned}
$$

Для визначення значення $\widehat{Y}$ Замовнику слід враховувати, якщо $\varphi(P) \equiv 0$, то для Виробника максимум прибутку $c P-\omega L$ досягається при $L^{*}=\left(\frac{c \alpha(1-\beta)}{\omega}\right)^{\frac{1}{\beta}} K$, а отже, при $P^{*}=\alpha K\left(\frac{c \alpha(1-\beta)}{\omega}\right)^{\frac{1-\beta}{\beta}}$, і дорівнює $\left(\frac{\omega \beta}{1-\beta}\right) L^{*}$. Якщо $\hat{P}>P^{*}$, то премія $\varphi(\hat{P})=(1-\delta)(s-c) \hat{P}$ може компенсувати Виробнику відхилення його прибутку від $\left(\frac{\omega \beta}{1-\beta}\right) L^{*}$.

Висновки. Наукова новизна даної статті полягає у розвитку теоретикометодичних засад проведення процедури визначення збоку замовника функції штрафів (заохочень) за допомогою параметризації функції. Це зроблено на основі побудованої моделі економічних відношень між замовником i виробником в дворівневій ієрархічній системі керування на короткотерміновий період часу для ефективного керування в цій системі збоку замовника. При цьому замовник прагне досягнути своєї мети, йдучи на певний компроміс i враховуючи цілі виробників. Крім того замовник стимулює виробників ефективно організовувати процес виробництва та використовувати ресурси (i ресурси часу), що є в їх розпорядженні. Цей механізм економічного керування можна використовувати, наприклад, в галузі сезонного будівництва, де діють такі випадкові чинники, як погодні умови, людський фактор. Якщо виробника не будуть влаштовувати значення премій в залежності від обсягів продукції, то сторони мають переглянути ціни $c$ або $s$, відсоток $\delta$. Подальше дослідження проблеми визначення функції штрафів (заохочень) за допомогою параметризації функції на основі отриманих результатів можливе у напрямку конкретизації параметрів задачі.

\section{Література:}

1. Моисеев Н.Н. Математические задачи системного анализа : учеб. пособ. [для студ. вузов] / Н.Н. Моисеев. - М.: «Наука», 1981. - 488 с.

2. Гермейер Ю.Б. Игры с непротивоположными интересами: монография / Ю.Б. Гермейер. - М.: «Наука», 1976. - 326 с.

3. Угольницкий Г.А. Устойчивое развитие организаций. Системный анализ, математические модели и информационные технологии управления. / Г.А. Угольницкий. М.: Изд-во физ.-мат. лит., 2011. - 320 с. 
4. Угольницкий Г.А. Иерархическое управление устойчивым развитием. / Г.А. Угольницкий. - М.: Изд-во физ.-мат. лит., 2010. - 336 с.

5. О некоторых подходах к моделированию воздействия промышленного сектора на экологию региона [Електронний ресурс] / Д.А. Поносов // Управление экономическими системами: электронный научный журнал. - 2011. - № 10. - С. 4. - Режим доступу до журн.: http://www.uecs.ru. 